\title{
Ganho de Peso, Conversão Alimentar, Ingestão Diária de Nutrientes e Digestibilidade de Garrotes Não-Castrados de Três Grupos Genéticos em Recria e Terminação ${ }^{1}$
}

\author{
Henrique Jorge Fernandes ${ }^{2}$, Mário Fonseca Paulino ${ }^{3}$, Renè Galvão Rezende Martins ${ }^{4}$, \\ Sebastião de Campos Valadares Filho ${ }^{3}$, Robledo de Almeida Torres ${ }^{3}$, Luísa Melville Paiva ${ }^{5}$, \\ George Frederico Bevitori Kling de Moraes $^{6}$
}

\begin{abstract}
RESUMO - Para se avaliar o desempenho (ganho de peso e conversão alimentar), o consumo de nutrientes e a digestibilidade aparente de vários nutrientes, foram utilizados 36 garrotes inteiros, 12 Nelore, 12 11/2 sangue Holandês-Nelore e 12 1/2 sangue Caracu-Nelore. Foram utilizados animais em recria, com peso inicial próximo a $205 \mathrm{~kg}$, e animais em terminação, com aproximadamente a $310 \mathrm{~kg}$. Os animais foram mantidos em regime de confinamento até o abate, realizado de acordo com peso: 310 a $330 \mathrm{~kg}$ PV para os animais em recria e 450 a 480 kg PV para aqueles em terminação. Foi fornecida a mesma dieta a todos os animais, com 50\% da matéria seca à base de concentrado e o restante de silagem pré-seca de coastcross. Os animais foram alimentados ad libitum e pesados a cada 28 dias. Foram retiradas amostras semanais de ração e de sobras individuais, que foram agrupadas em amostras para cada período de 28 dias. Realizou-se um ensaio de digestibilidade no 50ํㅡ dia de experimento. Não se observou efeito significativo de grupo genético sobre o consumo de matéria seca (6,06 kg/dia para recria e 9,05 kg/d para a terminação), ganho de peso vivo (0,994 kg/d e 1,293 kg/d para a recria e terminação, respectivamente) ou para os coeficientes de digestibilidade dos nutrientes analisados. Os animais $1 \frac{1}{2}$ sangue Caracu-Nelore da categoria recria apresentaram conversão alimentar 30\% maior que aqueles dos demais grupos genéticos. A ingestão de NDT esteve, em média, 26\% abaixo dos valores preditos pelo NRC (1996) para animais com estes pesos vivos e valores de ganho de peso.
\end{abstract}

Palavras-chave: consumo, desempenho, exigências, mestiços, Nelore

\section{Weigh Gain, Feed Conversion, Daily Ingestion of Nutrients and Apparent Digestibility of Bulls of Three Genetic Groups in Growing and Termination}

\begin{abstract}
Thirty-six young bulls (12 Nellore, 12 1 12 crossbred Holstein x Nellore, and 12 crossbred $1 / 2$ Caracu x Nellore) were used to evaluate weight gain, feed conversion, ingestion capacity and apparent digestibility of various nutrients. We use growing and finishing animals. The growing animals had initial weight of $205 \mathrm{~kg}$, and the finishing ones, initial weight of $310 \mathrm{~kg}$. The animals were fedlot to reach the weight of 310 to $330 \mathrm{~kg}$ for the growing animals and 450 to $480 \mathrm{~kg}$ for the finishing ones. The same diet was supplied to all animals, with concentrate level of $50 \%$ in the dry matter and $50 \%$ of coastcross hay silage. The animals were fed ad libitum and weighed every 28 days. Weekly samples of ration and individual orts were removed and composed for each period of 28 days. A digestibility test was done at the $50^{\text {th }}$ day of the experimental period. A significant effect of genetic group was not observed on dry matter intake (6.06 kg/day for the growing animals and $905 \mathrm{~kg} / \mathrm{d}$ for the finishing ones), live weight gain (0.994 and $1.293 \mathrm{~kg} / \mathrm{d}$ for growing and finishing animals), or digestibility coeficient of evaluated nutrients. The crossbred $1 \frac{1}{2}$ Caracu x Nellore growing animals presented higher feed conversion (30\%) than the other genetic groups. The TDN daily ingestion was 26\% smaller than the NRC (1996) predictions.
\end{abstract}

Key Words: productive performance, Nellore, crossbred, intake, requirements

\section{Introdução}

Entre as características produtivas do gado de corte, o ganho de peso é, sem dúvida, a mais estudada e a que mais diretamente se associa à produtividade de um rebanho. Por outro lado, a conversão alimentar representa a eficiência com que o animal converteu o alimento consumido em carne. Sob esta ótica, é economicamente mais importante a disseminação de material genético capaz de converter mais eficientemente o alimento, desde que se garanta qualidade mínima de carcaça, que propriamente maior desempenho em ganho de peso a baixo custo.

\footnotetext{
${ }^{1}$ Parte da Dissertação de Mestrado do primeiro autor. Projeto parcialmente financiado pela FAPEMIG.

${ }^{2}$ Professor do curso de Zootecnia da Universidade Estadual de Mato Grosso do Sul - UEMS (henrique@zootecnista.com.br).

${ }^{3}$ Professor do Departamento de Zootecnia da Universidade Federal de Viçosa - UFV (mpaulino@ufv.br).

${ }^{4}$ Médico Veterinário, Doutor em Zootecnia pela UFV (renegalvao@yahoo.com).

5 Professora do curso de Zootecnia da Universidade Estadual de Mato Grosso do Sul - UEMS (luisa@uems.br; lumelville@terra.com.br).

${ }^{6}$ Aluno do curso de Agronomia/UFV.
} 
Diversos trabalhos também têm registrado menores ganhos em animais zebuínos, quando estes são comparados a seus cruzamentos com taurinos, submetidos às mesmas condições de confinamento. Jorge et al. (1997) afirmam que a adoção de cruzamentos industriais permite elevar o potencial de ganho. Fontes (1995), revisando vários trabalhos realizados na Universidade Federal de Viçosa, constatou que o ganho de peso de animais mestiços foi, em média, 28,5\%, superior aos dos Nelore. Castillo Estrada et al. (1997) associaram este desempenho inferior dos animais Zebu a menores potenciais para ganho de massa muscular e conseqüente utilização de maior proporção da energia alimentar na deposição de gordura corporal (com menor eficiência de conversão). Véras et al. (2001b) consideram que animais tardios são ideais em sistemas de alto nível nutricional, uma vez que podem ser abatidos com pesos superiores, atingindo máximo desenvolvimento muscular, sem depósito excessivo de gordura. Por outro lado, Jorge et al. (1997) atribuíram o menor ganho de peso dos zebuínos ao menor consumo alimentar e à conversão alimentar inferior.

Ferreira et al. (1998) destacam que a conversão alimentar tem assumido grande importância com o avanço nos cruzamentos entre zebuínos e taurinos. Esses autores observaram, no entanto, que, além do grupo genético, também a inclusão de concentrados na dieta tem melhorado a conversão alimentar dos animais. Jorge et al. (1997) ressaltam que, apesar de alguns resultados indicarem melhor capacidade dos mestiços em digerir e utilizar o alimento, o grande volume de resultados controversos sugere que “... é necessária uma análise mais detalhada dos resultados para evitar-se conclusões precipitadas”. Shahin et al. (1993), citados por Castillo Estrada et al. (1997), observaram que a conversão alimentar também é influenciada pela velocidade e proporção com que os tecidos se depositam, concluindo que a composição do ganho poderia interferir diretamente na eficiência com que os alimentos são utilizados. Analisando dados de animais Nelore e de seus cruzamentos com Angus, Holandês e Normando, Castillo Estrada et al. (1997) não verificaram diferenças de consumo (expresso como \% do PV) entre grupos genéticos e atribuíram o menor ganho de peso dos animais Nelore ao menor potencial genético destes animais em depositar massa muscular. No entanto, neste experimento, como em outros citados pelos autores, não foram encontradas diferenças de conversão alimentar entre os animais Nelore e seus cruzamentos, o que poderia creditar o menor ganho de peso dos primeiros à menor ingestão diária total de alimentos (kg/dia) verificada para este grupo.

O desempenho de animais expostos a uma mesma dieta pode variar de acordo com quatro fatores: a maior ou menor capacidade de ingestão de alimentos; a capacidade de alguns animais de transformar a dieta fornecida por meio da seleção do material ingerido; a capacidade de determinados animais em aproveitar melhor o alimento ingerido; ou o potencial genético para ganho de peso dos animais (que pode atuar como limitante ao desempenho obtido).

A capacidade de ingestão de alimentos é o maior limitante à produção animal. Segundo Oliveira (1998), a ingestão voluntária de alimentos é fator que regula o crescimento, o ganho de peso e o acabamento dos animais. De modo geral, a alta correlação entre a produção de carne e a ingestão total de alimentos demonstra ser importante que se estudem os fatores capazes de influenciá-la e se determine como aproveitar as oportunidades de maximizá-la.

Segundo Jorge et al. (1998), parte da variação da capacidade dos ruminantes de consumir alimentos tem base genética. Entretanto, a magnitude da influência genética no consumo é de difícil determinação (Weston, 1982). Oliveira (1998) destaca que o consumo animal eleva proporcionalmente ao incremento da energia líquida de mantença do alimento, mas responde de forma curvilínea e não-linear ao aumento do nível de concentrado. Apesar disso, o autor cita ainda diversos fatores ligados ao animal que também interferem no consumo: raça, idade, sexo, tamanho, peso e condição corporal.

Jorge (1997) afirma que os resultados de trabalhos realizados no Brasil, comparando-se o consumo alimentar de zebuínos, taurinos e mestiços, têm se mostrado contraditórios. O autor cita diversos trabalhos realizados em condições brasileiras, em que o consumo de animais Nelore foi entre 88 e 103\% do consumo de seus mestiços. Esse autor salienta ainda a importância de se explorarem as possíveis diferenças dentro e entre grupos genéticos, utilizando-se a seleção. Hunter \& Siebert (1985), citados por Jorge et al. (1997), concluíram que os taurinos tem maior capacidade de consumo e eficiência de uso do alimentos quando se utilizam alimentos de boa qualidade, porém se igualam aos zebuínos quando este alimento é de média qualidade.

Forbes (1995) descreve que o consumo de bovi- 
nos de corte em crescimento pode ser comparado de forma mais efetiva quando expresso por unidade de tamanho animal.

Coelho da Silva \& Leão (1979) consideram a digestibilidade como uma característica do alimento, e não do animal. Deve-se reconhecer, no entanto, que fatores ligados ao animal e ao ambiente podem afetar a digestibilidade de determinado alimento. Van Soest (1994) define digestão como o processo de conversão de macromoléculas da dieta em compostos mais simples, que podem ser absorvidos no trato gastrointestinal (TGI) dos animais. Neste aspecto, alimentos de maior digestibilidade podem ser considerados como aqueles de maior valor nutritivo. No entanto, aspectos ligados ao animal (por exemplo, diferenças anatômicas no TGI, maior capacidade de secretar enzimas ou outras substâncias digestivas) ou ao manejo nutricional como um todo (por exemplo, taxa de passagem, interações entre alimentos, número de fornecimentos diários de alimento, quantidade de MS ingerida por dia, entre outros) podem interferir na digestibilidade de determinado alimento.

Objetivou-se, neste trabalho, avaliar o ganho de peso, a conversão alimentar, a capacidade de ingestão de nutrientes e a digestibilidade aparente de alguns nutrientes e comparar a ingestão diária de PB e NDT com o requerimento previsto pelo NRC (1996), utilizando-se bovinos de três grupos genéticos, alimentados com mesma dieta e abatidos com 310 a $330 \mathrm{~kg}$ e 450 a $480 \mathrm{~kg}$ de peso vivo, para as categorias recria e terminação, respectivamente.

\section{Material e Métodos}

O presente estudo foi realizado no Laboratório de Animais do Departamento de Zootecnia da Universidade Federal de Viçosa (UFV), em Minas Gerais.

Foram utilizados 36 garrotes inteiros, sendo 12 Nelore (Nel), $12 \mathrm{~F}_{1}$ Holandês x Zebu ( $\left.1 / 2 \mathrm{Hol}\right)$ e $12 \mathrm{~F}_{1}$ Caracu x Zebu ( $1 / 2$ Car), divididos em dois grupos, de acordo com o peso vivo inicial médio. Animais com peso inicial próximo a $205 \mathrm{~kg}$ e no máximo $240 \mathrm{~kg}$ foram definidos como representantes da categoria recria. Os animais com peso inicial próximo a $310 \mathrm{~kg}$ e no mínimo $290 \mathrm{~kg}$ foram classificados como pertencentes à categoria terminação. O experimento foi montado em delineamento inteiramente casualizado, com três tratamentos (grupos genéticos) e seis repetições (animais) para cada categoria de peso (recria e terminação).

\footnotetext{
R. Bras. Zootec., v.33, n.6, p.2403-2411, 2004 (Supl. 3)
}

Após um período de adaptação de sete dias, dois animais de cada tratamento (de cada grupo genético dentro de cada categoria) foram designados para o abate, servindo de referência no estudo da composição corporal. Portanto, nas análises de variância, foram utilizados dados de quatro animais por grupo genético por categoria.

Os animais restantes foram mantidos em regime de confinamento até o abate, realizado de acordo com o seguinte critério: 310 a 330 kg de peso vivo, para os animais do grupo recria, e 450 a $480 \mathrm{~kg}$ de peso vivo, para os animais do grupo terminação. Assim, o experimento não contou com um período experimental previamente definido. Apesar de os animais terem sido submetidos ao experimento simultaneamente, foram abatidos à medida que atingiram o peso de abate (houve, portanto um diferente período experimental para cada animal).

Foi fornecida a mesma dieta para todos os animais. Nesta dieta, 50\% da matéria seca foi constituída por concentrado à base de farelo de trigo, de farelo de soja e de milho (Tabela 1), devidamente suplementado com minerais. O volumoso, responsável pelos outros $50 \%$ da matéria seca da ração, foi silagem pré-seca de coastcross, adquirida de produtores comerciais. A dieta total foi balanceada, segundo as tabelas de exigência do NRC (1996), para ganho de peso vivo diário de 1,2 kg, utilizando-se o “Sistema Viçosa” (Lana, 2000) para ajuste da mes-

Tabela 1 - Composição percentual da dieta fornecida aos animais experimentais (\% na MS)

Table 1 - Percent composition of the diet fed to the experimental animals (\% in DM)

\begin{tabular}{lc}
\hline $\begin{array}{l}\text { Ingredientes } \\
\text { Ingredient }\end{array}$ & $\begin{array}{c}\text { MS (\%) } \\
\text { DM (\%) }\end{array}$ \\
\hline $\begin{array}{l}\text { Silagem pré-seca de coastcross } \\
\text { Pre dried coastcross silage }\end{array}$ & 50,0 \\
$\begin{array}{l}\text { Farelo de trigo } \\
\text { Wheat middling }\end{array}$ & 34,5 \\
$\begin{array}{l}\text { Milho } \\
\text { Corn }\end{array}$ & 12,5 \\
$\begin{array}{l}\text { Farelo de soja } \\
\text { Soybean meal } \\
\text { Mistura mineral* }\end{array}$ & \\
Mineral mix & 2,5 \\
\end{tabular}

* Calcário calcítico (Calcite limestone) 43,32\%; Cloreto de sódio (Sodium chlorate) 34,41\%; Flor de enxofre (Sulfur flower) 18,69\%; Sulfato de zinco (Zinc sulfate) $3,06 \%$; lodato de potássio (Potassium iodate) $0,22 \%$; Sulfato de cobalto (Cobalt sulfate) $0,2 \%$; Selenito de sódio (Sodium selenite) 0,1\%. 
Tabela 2 - Teores médios de matéria seca (MS), matéria orgânica (MO), proteína bruta (PB), extrato etéreo (EE), carboidratos totais (CHOT), fibra em detergente neutro (FDN), carboidratos não-fibrosos (CNF) e nutrientes digestíveis totais (NDT) da silagem, do concentrado e da dieta ${ }^{1}$

Table 2 - Average contents of dry matter (DM), organic matter (OM), crude protein (CP), ether extract (EE), total carbohydrates (CHOT), neutral detergent fiber (NDF), non fiber carbohydrates (NFC) and total digestible nutrients (TDN) of the silage, concentrate and diet

\begin{tabular}{|c|c|c|c|c|c|c|c|c|}
\hline & \multirow[t]{2}{*}{$\begin{array}{l}\text { MS (\%) } \\
D M(\%)\end{array}$} & \multicolumn{7}{|c|}{$\begin{array}{l}\text { Teores de nutrientes na matéria seca } \\
\text { Nutrients contents in the dry matter }\end{array}$} \\
\hline & & $\begin{array}{l}\text { MO (\%) } \\
\text { OM (\%) }\end{array}$ & $\begin{array}{l}\mathrm{PB}(\%) \\
C P(\%)\end{array}$ & $\begin{array}{l}\mathrm{EE}(\%) \\
\mathrm{EE}(\%)\end{array}$ & $\begin{array}{l}\text { СHOT(\%) } \\
\text { CHOT (\%) }\end{array}$ & $\begin{array}{l}\text { FDN (\%) } \\
\text { NDF (\%) }\end{array}$ & $\begin{array}{l}\text { CNF (\%) } \\
N F C(\%)\end{array}$ & $\begin{array}{c}\operatorname{NDT}(\%)^{2} \\
\operatorname{TDN}(\%)\end{array}$ \\
\hline $\begin{array}{l}\text { Silagem pré-seca } \\
\text { Pre dried silage }\end{array}$ & 48,00 & 92,05 & 16,87 & 2,49 & 72,69 & 69,60 & 3,09 & - \\
\hline $\begin{array}{l}\text { Concentrado } \\
\text { Concentrate }\end{array}$ & 86,30 & 95,53 & 16,40 & 3,18 & 75,95 & 26,26 & 49,69 & - \\
\hline $\begin{array}{l}\text { Dieta } \\
\text { Diet }\end{array}$ & 67,15 & 93,79 & 16,64 & 2,83 & 74,32 & 47,93 & 26,39 & 68,76 \\
\hline
\end{tabular}

ma. Os animais receberam, durante todo o período experimental, esta dieta balanceada ad libitum. $\mathrm{Na}$ Tabela 2, encontra-se a composição bromatológica da dieta fornecida aos animais.

A ração foi fornecida uma vez ao dia no início da manhã, completando-se os cochos vazios no período da tarde. Foram registradas as quantidades de ração fornecida e das sobras e coletadas semanalmente amostras de ração e de sobras individuais até o momento do abate do animal.

Os animais foram distribuídos em baias individuais, com piso concretado com área de $30 \mathrm{~m}^{2}$, sendo $8 \mathrm{~m}^{2}$ cobertos com telhas de amianto e $22 \mathrm{~m}^{2}$ de área descoberta, providas de bebedouro e comedouro de cimento.

Antes de se iniciar o experimento, os animais foram submetidos a controle de endo e ectoparasitas, foram identificados com brinco e receberam 2.000.000 de unidades internacionais de vitamina A.

Os animais foram pesados a cada 28 dias, e, à medida que um animal se aproximava do peso de abate pré-estabelecido, era definida a data de abate, a partir de uma projeção da evolução do peso vivo, com base no ganho de peso médio diário do último período. Antes do abate, os animais foram submetidos a um período de jejum de 16 horas.

O peso de corpo vazio dos animais foi calculado como descrito por Paulino et al. (1999). O ganho de peso de corpo vazio foi estimado como a diferença entre os pesos de corpo vazio inicial e final do animal.
Os ganhos médios diários de peso corporal vazio e de peso vivo foram calculados como o ganho de peso do período dividido pelo número de dias do intervalo de tempo considerado.

Para a conversão alimentar (CA), considerou-se como o total de MS ingerida durante o experimento dividido pelo ganho de peso de corpo vazio (GPvz) total.

As amostras semanais de ração e de sobras individuais foram acondicionadas em sacos de papel e pré-secas em estufa de ventilação forçada, a 55$60^{\circ} \mathrm{C}$, durante de 48 horas. Em seguida, foram processadas em moinho (tipo "Willey” com peneira de 30 "mesh") e agrupadas de forma proporcional (de acordo com o total de sobras de cada semana), constituindo-se amostras compostas para cada período de 28 dias, para posteriores análises químicas.

As determinações de nitrogênio total foram feitas em aparelhos semimicro Kjeldahl; as de extrato etéreo, no aparelho Goldfish; as de cinza, em mufla elétrica a $600^{\circ} \mathrm{C}$; e as de $\mathrm{FDN}$, em aparelho próprio, todas conforme a metodologia descrita por Silva (1990). Os teores de carboidratos totais (CHOT) foram determinados pela diferença entre o total de matéria orgânica e o somatório dos totais de PB eEE. Os teores de carboidratos não-fibrosos (CNF), por sua vez, foram determinados pela diferença entre CHOT e FDN.

Comparou-se a ingestão diária de NDT e de PB com os valores preditos, segundo as equações do NRC (1996). 
Foi realizado ensaio de digestibilidade aos 50 dias de experimento, utilizando-se todos os animais. $\mathrm{O}$ período de coleta teve duração de seis dias, durante os quais se procedeu à amostragem do alimento consumido, das sobras e das fezes. Amostras de fezes foram coletadas no chão logo após defecação ou, alternativamente, diretamente do reto dos animais, em dois períodos (manhã e tarde), sendo a coleta da manhã realizada nos primeiros dias do período de coleta e a coleta da tarde, nos últimos dias. As amostras foram homogeneizadas, acondicionadas em pratos de alumínio e pré-secas em estufa de ventilação forçada, a $55-60^{\circ} \mathrm{C}$, durante 72 horas. Em seguida, foram processadas em moinho tipo "Willey" com peneira de 30 "mesh" e agrupadas de forma proporcional, constituindo-se amostras compostas de cada animal para posteriores análises.

Empregou-se o indicador interno fibra detergente ácido insolúvel (FDAi) para se estimar a produção de matéria seca fecal (MSF), conforme proposto por Cochran et al. (1986). Entretanto, utilizou-se incubação ruminal em sacos de náilon, por 144 horas, em vez da digestibilidade in vitro sugerida pelos autores. $\mathrm{O}$ total de matéria seca fecal (MSF) foi calculado segundo a equação:

\section{$\mathrm{kg}$ de MSF estimada = \\ kg de indicador ingerido \\ $\%$ do indicador nas fezes}

Os dados de ganho médio diário, conversão alimentar e ingestão média diária de nutrientes e os coeficientes de digestibilidade dos diferentes nutrientes foram analisados em cada categoria em delineamento inteiramente casualizado com três tratamentos constituídos pelos grupos genéticos. Utilizou-se o peso de corpo vazio dos animais (PCVZ) como covariável para ajustar seu efeito nas comparações entre os três grupos genéticos. Em todas as análises realizadas, as pressuposições da ANOVA e da ANCOVA foram checadas. Quando verificado efeito significativo de grupo genético nas ANOVAS, as médias ajustadas por quadrados mínimos foram comparadas pelo teste de Tukey, a 5\% de significância, para todas as análises realizadas. Utilizou-se o procedimento GLM (proc GLM) do SAS (1989) para a realização das análises de variância e dos testes de comparação de médias.

Para estimativa das equações de regressão da ingestão diária de nutrientes, em função das exigências preditas pelo NRC (1996), utilizou-se o procedimento REGRESSION (proc REG) do SAS (SAS, 1989).

Empregou-se o programa SAS (SAS, 1989), licenciado para a Universidade Federal de Viçosa em 2001.

\section{Resultados e Discussão}

Uma vez que os animais foram submetidos à mesma dieta e ao mesmo manejo alimentar, esperase que as diferenças de consumo encontradas estejam ligadas a fatores inerentes ao animal.

Não foram observadas diferenças significativas $(\mathrm{P}>0,05)$ entre grupos genéticos quando se avaliou o consumo ajustado para o PCVZ (Tabela 3). Isto indica que as eventuais diferenças de consumo observadas entre grupos genéticos podem ser explicadas pelas diferenças de peso entre os animais dos grupos genéticos avaliados.

O NRC (1996) relaciona a capacidade de ingestão de alimentos ao tamanho corporal dos animais e cita, especificamente, animais da raça Holstein e seus cruzamentos com raças britânicas de corte como exemplo de animais com capacidade de consumir uma maior quantidade de alimentos em relação ao seu peso vivo. Além disto, este comitê associa ainda a capacidade de ingestão de alimentos do animal ao seu potencial genético para crescimento. Desse modo, animais com maior potencial genético para crescimento (e maior demanda nutricional) poderiam apresentar maior consumo alimentar.

Trabalhos realizados em condições brasileiras (Jorge et al., 1997; Castilho Estrada, 1996; Galvão et al., 1991) têm registrado tendência de menor consumo de MS (expresso em kg/dia) para animais Nelore quando comparados com seus mestiços.

A ausência de diferenças significativas entre a capacidade de consumo relativo ao peso vivo dos diferentes grupos genéticos avaliados neste estudo pode ser atribuída às pequenas diferenças observadas entre o tamanho do TGI dos animais Nelore e de seus cruzamentos (Fernandes, 2001) e ao potencial genético de crescimento semelhante entre estes animais. As semelhanças registradas (Tabela 3) entre os grupos genéticos quanto à ingestão diária de FDN (associada ao mecanismo de limitação física do consumo) e de NDT (associada ao mecanismo de limitação química do consumo e à demanda energética do animal) vêm reforçar esta teoria.

As médias de consumo relativo (\%PV) constantes na Tabela 3 foram maiores que as encontradas por

R. Bras. Zootec., v.33, n.6, p.2403-2411, 2004 (Supl. 3) 
Tabela 3 - Médias de quadrado mínimos da ingestão diária de matéria seca (IDMS), proteína bruta (IDPB), fibra em detergente neutro (IDFDN) e nutrientes digestíveis totais (IDNDT) de três grupos genéticos nas categorias recria e terminação

Table 3 - Least square means of daily ingestion of dry matter (DIDM), crude protein (DICP), neutral detergent fiber (DINDF) and total digestible nutrients (DITDN) of three genetic groups in the growing and finishing phases

\begin{tabular}{|c|c|c|c|c|c|c|c|c|}
\hline \multirow[b]{2}{*}{$\begin{array}{l}\text { Grupos genéticos } \\
\text { Genetic groups }\end{array}$} & \multicolumn{4}{|c|}{$\begin{array}{l}\text { Recria } \\
\text { Growing }\end{array}$} & \multicolumn{4}{|c|}{$\begin{array}{l}\text { Terminação } \\
\text { Finishing }\end{array}$} \\
\hline & $1 / 2$ Car & $1 / 2 \mathrm{Hol}$ & $\mathrm{Nel}$ & CV (\%) & $1 / 2 \mathrm{Car}$ & $1 / 2 \mathrm{Hol}$ & $\mathrm{Nel}$ & CV (\%) \\
\hline $\begin{array}{l}\text { IDMS (kg/dia) } \\
\text { DIDM (kg/day) }\end{array}$ & 5,96 & 5,94 & 6,17 & 7,83 & 9,13 & 9,38 & 8,25 & 7,96 \\
\hline $\begin{array}{l}\text { IDMS (\%PV) } \\
\text { DIDM }(\% L W)\end{array}$ & 2,14 & 2,14 & 2,24 & 6,44 & 2,31 & 2,35 & 2,11 & 7,98 \\
\hline $\begin{array}{l}\text { IDPB (kg/dia) } \\
\text { DICP (kg/day) }\end{array}$ & 0,99 & 0,98 & 1,02 & 7,94 & 1,52 & 1,56 & 1,37 & 7,99 \\
\hline $\begin{array}{l}\text { IDFDN (kg/dia) } \\
\text { DINDF (kg/day) }\end{array}$ & 2,83 & 2,81 & 2,93 & 8,16 & 4,35 & 4,45 & 3,90 & 8,33 \\
\hline $\begin{array}{l}\text { IDFDN (\% PV) } \\
\text { DINDF }(\% L W)\end{array}$ & 1,01 & 1,01 & 1,06 & 6,76 & 1,10 & 1,12 & 1,00 & 8,29 \\
\hline $\begin{array}{l}\text { IDNDT (kg/dia) } \\
\text { DITDN (kg/day) }\end{array}$ & 4,20 & 4,06 & 4,30 & 8,18 & 6,21 & 6,32 & 5,67 & 9,54 \\
\hline
\end{tabular}

$\mathrm{CV}=$ coeficiente de variação (coefficient of variation).

Castillo Estrada (1996), mas menores que as relatadas por Galvão et al. (1991) e Guimarães (1999) e bem semelhantes às reportadas por Jorge (1993) e por Ferreira et al. (1998).

Comparando-se a ingestão diária de proteína e de NDT e as exigências preditas pelas equações do NRC (1996) para animais com estes pesos e ganhos diários, observa-se consumo de PB de 19 a $80 \%$ acima do previsto, concomitante a uma ingestão de NDT de 8 a $37 \%$ abaixo do previsto. Estas observações são coerentes com um fornecimento excessivo de $\mathrm{PB}$, decorrente do alto teor de PB na silagem utilizada. As baixas ingestões de energia (expressa como NDT), por sua vez, são coerentes com trabalhos desenvolvidos em condições brasileiras (Freitas, 1995; Paulino et al., 1999; e Véras et al., 2001a), que têm comprovado exigências nutricionais de energia inferiores àquelas preditas pelo NRC (1996). Estes resultados permitem inferir, ainda, que a ingestão de energia foi o fator mais limitante à produção dos animais experimentais.

A análise de variância não indicou efeito $(\mathrm{P}>0,05)$ de grupo genético em nenhuma das categorias para os coeficientes de digestibilidade dos nutrientes avaliados (Tabela 4). O efeito de grupo genético sobre a digestibilidade dos nutrientes tem sido objeto de controvérsia. Enquanto alguns trabalhos têm evidenciado diferenças na digestibilidade de nutrientes entre zebuínos, taurinos e seus mestiços, outros não têm registrar diferenças significativas nesta característica (Andrade, 1992; Castillo Estrada, 1996). As diferenças citadas por estes autores (e outros mencionados por eles) referem-se, em geral, à maior capacidade de animais Nelore de digerirem os nutrientes, especialmente quando expostos à dietas de baixa qualidade, com altos teores de fibra. Esta capacidade, quando observada, tem sido atribuída principalmente ao menor consumo matéria seca dos animais Nelore e, eventualmente, às diferenças anatômicas e fisiológicas entre os grupos genéticos.

No presente experimento, a boa qualidade da dieta oferecida, a falta de diferença na ingestão de matéria seca entre os grupos genéticos e o fato de que todos os animais possuíam pelo menos $50 \%$ de sangue Nelore podem explicar a semelhança dos coeficientes de digestibilidade observados.

Os valores de coeficiente de digestibilidade para os diversos nutrientes foram, em geral, superiores, aqueles identificados por Castillo Estrada (1996). Os maiores teores de FDN nas dietas utilizadas por este autor podem justificar as diferenças encontradas. Os dados apresentados por Véras et al. (2000) foram bastante semelhantes aos obtidos neste experimento. Da mesma forma, quando trabalhou com silagem de milho como volumoso, Andrade (1992) 
Tabela 4 - Médias de quadrados mínimos dos coeficientes de digestibilidade (\%) de matéria seca (CDMS), matéria orgânica (CDMO), proteína bruta (CDPB), extrato etéreo (CDEE), carboidratos totais (CDCHO), carboidratos não-fibrosos (CDCNF) e fibra em detergente neutro (CDFDN) em três grupos genéticos, nas categorias recria e terminação

Table 4 - Least square means of the coefficients of digestibility (\%) of dry matter (CDDM), organic matter (CDOM), crude protein $(C D C P)$, ether extract (CDEE), total carbohydrates (CDCHO), non fiber carbohydrates (CDNFC) and neutral detergent fiber (DINDF) of three genetic groups in the growing and finishing phases

\begin{tabular}{|c|c|c|c|c|c|c|c|c|}
\hline \multirow[b]{2}{*}{$\begin{array}{l}\text { Grupos genéticos } \\
\text { Genetic groups }\end{array}$} & \multicolumn{4}{|c|}{$\begin{array}{l}\text { Recria } \\
\text { Growing }\end{array}$} & \multicolumn{4}{|c|}{$\begin{array}{l}\text { Terminação } \\
\text { Finishing }\end{array}$} \\
\hline & $1 / 2$ Car & $1 / 2 \mathrm{Hol}$ & Nel & CV (\%) & $1 / 2$ Car & $1 / 2 \mathrm{Hol}$ & Nel & CV $(\%)$ \\
\hline CDMS (CDDM) & 71,24 & 69,06 & 70,46 & 3,91 & 68,35 & 67.75 & 68,86 & 4,42 \\
\hline CDMO (CDOM) & 72,13 & 70,30 & 71,39 & 3,89 & 69,68 & 69,05 & 70,33 & 4,17 \\
\hline $\mathrm{CDPB}(C D C P)$ & 75,49 & 72,08 & 74,47 & 4,40 & 72,26 & 71,56 & 70,70 & 4,70 \\
\hline $\operatorname{CDEE}(C D E E)$ & 81,90 & 78,48 & 75,86 & 4,02 & 76,35 & 76,99 & 81,57 & 8,36 \\
\hline CDCHOT (CDCHOT) & 71,01 & 69,59 & 70,55 & 3,87 & 68,85 & 68,20 & 69,81 & 4,33 \\
\hline CDCNF (CDNFC) & 87,34 & 88,69 & 89,52 & 3,05 & 87,41 & 87,73 & 86,58 & 2,75 \\
\hline CDFDN (CDNDF) & 61,79 & 58,87 & 59,98 & 5,53 & 58,47 & 57,30 & 60,28 & 6,22 \\
\hline
\end{tabular}

$\mathrm{CV}=$ coeficiente de variação (coefficient of variation).

encontrou resultados para CDMO próximos aos obtidos nesta pesquisa, enquanto nos grupos alimentados com volumosos de pior qualidade os coeficientes de digestibilidade foram menores.

A análise de variância da conversão alimentar comprovou efeito $(\mathrm{P}<0,05)$ de grupo genético dentro da categoria recria (Tabela 5). A principal diferença encontrada foi o maior valor apresentado pelos $1 / 2$ Car, em decorrência do baixo ganho de peso ajustado para PCVZ apresentado por estes animais nesta categoria (Tabela 6), que pode estar associado às condições pré-experimentais. Pode-se inferir que houve superalimentação sofrida pelos animais $1 \frac{1}{2} \mathrm{Car}$ da categoria recria antes de serem enviados ao experimento, o que pode tê-los levado a uma condição corporal que dificulta o ganho de peso, na medida em que desenvolveram os órgãos e vísceras, incrementando também as exigências de mantença destes animais. Esta hipótese é suportada pela condição corporal apresentada por estes animais no início dos trabalhos.

Guimarães (1999) também destaca a importância da massa de órgãos internos metabolicamente ativos na conversão alimentar e atribui parte da melhor conversão alimentar observada em animais sob ganho compensatório à menor massa de órgãos metabolicamente ativos. Dessa forma, os melhores valores de conversão observados para os animais Nelore da recria, no presente experimento, podem ser atribuídos a um ganho compensatório destes animais no início dos trabalhos.

Os valores de conversão alimentar na categoria terminação não apresentaram efeito $(\mathrm{P}>0,05)$ de grupo genético e foram bastante próximos aos observados por Ferreira et al. (1998) em mestiços de corte alimentados com dietas contendo $50 \%$ de concentrado, e menores que os encontrados por Galvão et al. (1991), em animais Nelore alimentados com a mesma relação volumoso:concentrado. A conversão observada em animais cruzados no presente experimento foi maior ainda que os valores relatados por Castillo Estrada (1996) e Jorge et al. (1997) para animais Nelore ou Cruzados.

Uma vez que a conversão alimentar pode estar associada à composição do ganho de peso dos animais, o fato de ter trabalhado com animais não-castrados, abatidos a um peso não muito elevado (favorecendo a predominância de crescimento de tecido muscular, independentemente da precocidade do grupo genético), pode explicar, em parte, a semelhança observada nos valores de conversão alimentar dos animais terminação. Esta hipótese é suportada pela participação do tecido muscular no ganho de peso vivo destes animais (em torno de 50\%), semelhante para todos os grupos genéticos (Fernandes, 2001).

Castillo Estrada (1996), Jorge et al. (1997) e Jorge et al. (1998) também não observaram diferenças nas eficiências de ganho diário, ao trabalharem com diversos grupos genéticos, submetidos a condições nutricionais semelhantes às deste expe-

R. Bras. Zootec., v.33, n.6, p.2403-2411, 2004 (Supl. 3) 
Tabela 5 - Médias de quadrados mínimos da conversão alimentar (kg MS ingerida/kg de ganho) em relação ao ganho de peso de corpo vazio (CAvz) e ao ganho de peso vivo (CAv) de três grupos genéticos nas categorias recria e terminação

Table 5 - Least square means of feed:gain ratio ( $\mathrm{kg} \mathrm{DM}$ ingested $/ \mathrm{kg}$ of gain) in relation to the empty body weight gain $\left(F / G_{e p}\right)$ and to live weight gain $\left(F / G_{p}\right)$ of three genetic groups in the growing and finishing phases

\begin{tabular}{|c|c|c|}
\hline $\begin{array}{l}\text { Grupo genético } \\
\text { Genetic group }\end{array}$ & $\begin{array}{l}\text { CAvz } \\
F / G_{e p}\end{array}$ & $\begin{array}{l}\text { CAv } \\
F / G_{l}\end{array}$ \\
\hline & \multicolumn{2}{|c|}{ Recria } \\
\hline 1/2 Car & $9,34^{\mathrm{a}}$ & $8,35^{a}$ \\
\hline $1 / 2 \mathrm{Hol}$ & $5,77^{b}$ & $5,09^{b}$ \\
\hline Nel & $5,23^{b}$ & $4,80^{b}$ \\
\hline CV (\%) & 10,88 & 4,47 \\
\hline & \multicolumn{2}{|c|}{$\begin{array}{l}\text { Terminação } \\
\text { Finishing }\end{array}$} \\
\hline $1 / 2 \mathrm{Car}$ & $7,29^{\mathrm{a}}$ & $6,66^{\mathrm{a}}$ \\
\hline $1 / 2 \mathrm{Hol}$ & $7,81^{\mathrm{a}}$ & $6,98^{a}$ \\
\hline Nel & $7,42^{a}$ & $7,32^{\mathrm{a}}$ \\
\hline CV(\%) & 10,58 & 13,04 \\
\hline
\end{tabular}

$\mathrm{CV}=$ coeficiente de variação (coefficient of variation). Pares de médias na mesma coluna, dentro da mesma categoria, seguidos por pelo menos uma mesma letra, não diferem pelo teste de Tukey a 5\% de significância.

Couple of means, in the same column, within the same category, followed by at least one same letter, do not differ by Tukey test, at $5 \%$ of significance.

Tabela 6 - Médias de quadrados mínimos do ganho médio diário de peso de corpo vazio (GMDVz) e de peso vivo (GMDv), expressos em $\mathrm{kg} / \mathrm{dia}$, e relação GMDvz/GMDv de três grupos genéticos nas categorias recria e terminação Table 6 - Least square means of the daily empty body weight gain $\left(D L W_{e p}\right)$ daily live weight gain $(D L W)$, in $\mathrm{kg} /$

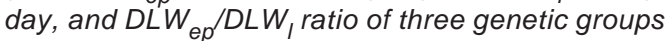
in the growing and finishing phases

\begin{tabular}{|c|c|c|c|}
\hline $\begin{array}{l}\text { Grupo genético } \\
\text { Genetic group }\end{array}$ & $\begin{array}{l}\text { GMDvz } \\
\text { (kg/dia) } \\
D L W_{e p} \\
\text { (kg/day) }\end{array}$ & $\begin{array}{c}\text { GMDv } \\
\text { (kg/dia) } \\
D L W_{l} \\
\text { (kg/day) }\end{array}$ & $\begin{array}{c}\text { Rel. GMDvz/ } \\
\text { GMDv } \\
D L W_{e p} / D L W_{l} \\
\text { ratio }\end{array}$ \\
\hline & & $\begin{array}{l}\text { Recria } \\
\text { Growing }\end{array}$ & \\
\hline $1 / 2 \mathrm{Car}$ & $0,595^{\mathrm{a}}$ & $0,653^{a}$ & 0,9112 \\
\hline $1 / 2 \mathrm{Hol}$ & $0,998^{\mathrm{b}}$ & $1,136^{b}$ & 0,8785 \\
\hline $\mathrm{Nel}$ & $1,120^{\mathrm{b}}$ & $1,229^{b}$ & 0,9113 \\
\hline CV (\%) & 7,92 & $\begin{array}{l}10,48 \\
\text { Terminação } \\
\text { Finishing }\end{array}$ & \\
\hline $1 / 2$ Car & $1,257^{a}$ & $1,397^{a}$ & 0,8998 \\
\hline $1 / 2 \mathrm{Hol}$ & $1,207^{\mathrm{a}}$ & $1,353^{\mathrm{a}}$ & 0,8921 \\
\hline $\mathrm{Nel}$ & $1,124^{\mathrm{a}}$ & $1,148^{\mathrm{a}}$ & 0,9791 \\
\hline CV (\%) & 12,92 & 13,77 & \\
\hline
\end{tabular}

Pares de médias na mesma coluna, dentro da mesma categoria, seguidos por pelo menos uma mesma letra, não diferem pelo teste de Tukey a 5\% de significância.

Couple of means, in the same column, within the same category, followed by at least one same letter, do not differ by Tukey test, at $5 \%$ of significance.

R. Bras. Zootec., v.33, n.6, p.2403-2411, 2004 (Supl. 3) rimento. Estes autores também relacionaram este resultado às semelhanças observadas na composição de ganho dos animais.

A análise do ganho de peso de corpo vazio e de peso vivo, ajustados para o PCVZ, dos animais da categoria terminação, não mostrou efeito $(\mathrm{P}>0,05)$ de grupo genético (Tabela 6). Estes valores foram menores que os encontrados por diversos autores que compararam animais Nelore aos seus mestiços (Jorge et al., 1998; Jorge et al., 1997; Castillo Estrada, 1996). Grande parte dos trabalhos realizados até o momento, no entanto, não evidenciou diferenças significativas, ou apresentaram resultados controversos quanto ao potencial de ganho de peso de diferentes grupos genéticos. Assim, em algumas ocasiões, como observado na categoria recria, o Nelore parece apresentar tendência a maiores ganhos de peso que os mestiços (Jorge et al., 1998). Estes autores atribuem esta maior capacidade de ganho dos animais Nelore ao fato de estes terem sido submetidos a uma seleção mais intensa, direcionada exclusivamente para produção de carne. Jorge et al. (1997) relataram que, quando comparado a mestiços europeus-zebu de origem de corte, o Nelore tende a apresentar menores ganhos de peso. Também Galvão et al. (1991) e Castilllo Estrada (1996) relataram menores ganhos de peso para animais Nelore, quando comparados com mestiços de corte.

\section{Conclusões}

Os animais $1 / 2$ Car da categoria recria apresentaram baixo ganho de peso, o que levou a altos valores de conversão alimentar para este grupo.

Não se observaram variações significativas na ingestão diária de matéria seca e no coeficiente de digestibilidade dos nutrientes entre os diferentes grupos genéticos avaliados.

A ingestão de NDT esteve, em média, cerca de 26\% abaixo dos valores preditos pelo NRC(1996) para animais com estes pesos vivos e ganhos de peso.

\section{Literatura Citada}

ANDRADE, A.T. Digestão total e parcial da matéria seca, matéria orgânica, energia bruta e proteína bruta em diferentes grupos genéticos de bovídeos. Viçosa, MG: Universidade Federal de Viçosa, 1992. 150p. Tese (Doutorado em Zootecnia) - Universidade Federal de Viçosa, 1992. CASTILLO ESTRADA, L.H. Composição corporal e exigências de proteína, energia e macroelementos minerais (Ca, 
P, Mg, Na e K), características da carcaça e desempenho do Nelore e mestiços em confinamento. Viçosa, MG: Universidade Federal de Viçosa, 1996. 129p. Tese (Doutorado em Zootecnia) - Universidade Federal de Viçosa, 1996.

CASTILLO ESTRADA, L.H.; FONTES, C.A.A.; JORGE, A.M. et al. Exigências Nutricionais de bovinos não castrados em confinamento. 1. Conteúdo corporal e exigências líquidas de proteína e energia para ganho de peso. Revista Brasileira de Zootecnia, v.26, n.3, p.575-583, 1997.

COCHRAN, R.C.; ADAMS, D.C.; WALLACE, J.D. Predicting digestibility diets with internal markers: evaluation of four potential markers. Journal of Animal Science, v.63, p.1476-1483, 1986.

COELHO DA SILVA, J.F.; LEÃO, M.I. Fundamentos de nutrição dos ruminantes. Piracicaba: Livroceres, 1979. 384p.

FERNANDES, H.J. Desempenho produtivo, digestibilidade e composição corporal de bovinos de três grupos genéticos na recria e na terminação. Viçosa, MG: Universidade Federal de Viçosa, 2001. 72p. Dissertação (Mestrado em Zootecnia) - Universidade Federal de Viçosa, 2001.

FERREIRA, M.A.; VALADARES FILHO, S.C.; COELHO DA SILVA, J.F. et al. Consumo, conversão alimentar, ganho de peso e características da carcaça de bovinos F1 Simental x Nelore. Revista Brasileira de Zootecnia, v.28, n.2, p.343-351, 1998.

FONTES, C.A.A. Composição corporal, exigências liquidas de nutrientes para ganho de peso e desempenho produtivo de animais zebuínos e mestiços europeu-zebu. Resultados experimentais. In: SIMPÓSIO INTERNACIONAL SOBRE EXIGÊNCIAS NUTRICIONAIS DE RUMINANTES, 1995, Viçosa, MG. Anais... Viçosa, MG: Universidade Federal de Viçosa, 1995. p.419-455.

FORBES, J.M. Voluntary food intake and diet selection in farm animals. Biddles: Cab International, 1995. 532p.

FREITAS, J.A. Composição corporal e exigência de energia e proteína de bovinos (zebuínos e mestiços) e bubalinos não castrados, em confinamento. Viçosa, MG: Universidade Federal de Viçosa, 1995. 75p. Dissertação (Mestrado em Zootecnia) - Universidade Federal de Viçosa, 1995.

GALVÃO, J.G.; FONTES, C.A.A.; PIRES, C.C. et al. Ganho de peso, consumo e conversão alimentar em bovinos nãocastrados, de três grupos raciais, abatidos em diferentes estágios de maturidade (estudo 1). Revista Brasileira de Zootecnia, v.20, n.5, p.495-501, 1991.

GUIMARÃES, R.F. Ganho de peso, consumo e conversão alimentar, composição corporal e características de carcaça de novilhos mestiços durante o ganho compensatório. Viçosa, MG: Universidade Federal de Viçosa, 1999. 111p. Dissertação (Mestrado em Zootecnia) - Universidade Federal de Viçosa, 1999.

JORGE, A.M.; FONTES, C.A.A.; PAULINO, M.F. et al. Desempenho produtivo de animais de quatro raças zebuínas, abatidos em três estádios de maturidade. 1. Ganho de peso e de carcaça e eficiência de ganho. Revista Brasileira de Zootecnia, v.27, n.4, p.766-769, 1998.

JORGE, A.M. Desempenho produtivo, características e composição corporal e da carcaça de zebuínos de quatro raças, abatidos em diferentes estágios de maturidade. Viçosa, MG: Universidade Federal de Viçosa, 1997. 99p. Tese (Doutorado em Zootecnia) - Universidade Federal de Viçosa, 1997.
JORGE, A.M.; FONTES, C.A.A.; FREITAS, J.A. et al. Ganho de peso e de carcaça, consumo e conversão alimentar de bovinos e bubalinos, abatidos em dois estádios de maturidade. Revista Brasileira de Zootecnia, v.26, n.4, p.806-812, 1997.

JORGE, A.M. Ganho de peso, conversão alimentar e características da carcaça de bovinos e bubalinos. Viçosa, MG: Universidade Federal de Viçosa, 1993. 97p. Dissertação (Mestrado em Zootecnia) - Universidade Federal de Viçosa, 1993.

LANA, R.P. Sistema Viçosa de formulação de rações. Viçosa, MG: Universidade Federal de Viçosa, 2000. 60p.

OLIVEIRA, S.R. Desempenho e características da carcaça de novilhos Nelore não castrados. Viçosa, MG: Universidade Federal de Viçosa, 1998. 58p. Dissertação (Mestrado em Zootecnia) - Universidade Federal de Viçosa, 1998.

NATIONAL RESEARCH COUNCIL - NRC. Nutrient requirements of beef cattle. 7.ed. Washington, D.C.: National Academy of Science, 1996. 242p.

PAULINO, M.F.; FONTES, C.A.A.; JORGE, A.M. et al. Exigências de energia para mantença de bovinos zebuínos nãocastrados em confinamento. Revista Brasileira de Zootecnia, v.28, n.3, p.621-626, 1999.

STATISTICAL ANALYSES SYSTEM - SAS. SAS/STAT user's guide, Version 6. 4.ed. Cary: 1989. 943p.

SNIFFEN, C.J.; O’CONNOR, J.D.; Van SOEST, P.J. et al. A net carbohydrate and protein system for evaluating cattle diets: II - Carbohydrate and Protein availability. Journal of Animal Science, v.70, p.3562-3577, 1992.

SILVA, D.J. Análise de alimentos: métodos químicos e biológicos. Viçosa, MG: Universidade Federal de Viçosa, 1990. 165p.

Van SOEST, P.J. Nutritional ecology of the ruminant. 2.ed. Ithaca: Cornell University Press, 1994. 476p.

VÉRAS, A.S.C.; VALADARES FILHO, S.C.; COELHO DA SILVA, J.F. et al. Consumo e digestibilidade aparente em bovinos Nelore, não-castrados, alimentados com rações contendo diferentes níveis de concentrado. Revista Brasileira de Zootecnia, v.29, n.6, p.2367-2378, 2000.

VÉRAS, A.S.C.; VALADARES FILHO, S.C.; COELHO DA SILVA, J.F. et al. Eficiência de utilização da energia metabolizável para mantença e ganho de peso e exigências de energia metabolizável e de nutrientes digestíveis totais de bovinos Nelore, não-castrados. Revista Brasileira de Zootecnia, v.30, n.3, p.904-910, 2001.

VÉRAS, A.S.C.; VALADARES FILHO, S.C.; COELHO DA SILVA, J.F. et al. Predição da composição corporal e dos requisitos de energia e proteína para ganho de peso de bovinos, não-castrados, alimentados com rações contendo diferentes níveis de concentrados. Revista Brasileira de Zootecnia, v.30, n.3, p.1127-1134, 2001.

WESTON, R. Animal factors affecting feed intake. In: NUTRITIONAL LIMITS TO ANIMAL PRODUCTION FROM PASTURE, 1982, Sta. Lúcia. Proceedings... Sta. Lúcia: Queens, 1982. p.183-198.

Recebido em: 04/02/03 Aceito em: 03/06/04 